\title{
Elaborating Screening Scales for Early Diagnosis of Developmental Delay in Five- to Six-Year-Old Children in Russia
}

\author{
Andrey D. Nasledov, Sergey A. Miroshnikov*, Liubov O. Tkacheva, \\ Oksana V. Zashchirinskaia, Vadim A. Goncharov \\ Department of Pedagogy and Pedagogical Psychology, Saint Petersburg State University, \\ Saint Petersburg, Russia
}

*Corresponding author. E-mail: sergeyamir@gmail.com

Background. It is known that the earlier a child is diagnosed with developmental delay (DD), the more promising his/her cognitive development can be. Various screenings are used worldwide for early detection of developmental problems. However, timely diagnosis of DD is not sufficiently carried out in Russia at present.

Objective. Elaboration of screening scales to quickly monitor the mental development of five- to six-year-old Russian children was the objective of this study. The scales we developed involved the use of modern information technologies to obtain reliable results.

Design. This study was carried out with a sample of 1,860 children. The formal procedure for multilateral monitoring of child development was used for data collection, involving a much more extensive set of tasks than in traditional tests of abilities; this allowed for a wider variation of the factor structure. For the fiveyear-olds, 349 tasks were used, and 292 for the six-year-olds. To construct scales for each age group (six-seven items in each), which would most accurately predict the diagnosis (Norm or DD), factor and discriminant analysis were carried out. To verify the prediction model, structural equation modeling (SEM) was used.

Results. As a result of the study, we developed scales which had similar types of variables for each age group (simpler for the five-year-olds and more complex for the six-year-olds). The common variables were logical reasoning, motor skills, and general awareness; two other scales were added for the six-year-olds: sustained attention and counting. According to the SEM, these scales are indicators of the general ability factor, and the latter one (general awareness) is the main predictor of the diagnosis.

Conclusions. Short scales for rapid identification of DD in Russian preschoolers were constructed, which allow the use of computer technology to uncover the risk group among five- and six-year-olds in a timely fashion, and have high sensitivity and specificity of the forecast (not lower than $94 \%$ ).

Keywords screening; developmental delay (DD); construction of scales; structural equation modeling (SEM); five- to six-year-olds 


\section{Introduction}

The age of six represents a significant shift from earlier age ranges, in that it is a threshold between a relaxed childhood and the beginning of systematic school education for Russian children. The current education system mandates special requirements for typically developing six-year-olds, so that by the beginning of school, children must have already mastered the primary skills of reading, writing, and counting. Thus, at the age of five to six years, it is especially important to assess the level of a child's cognitive development, because there is still time to correct problems. At the same time, it is necessary at that time to specify the optimal educational route, taking into account the individual characteristics of the child's development, should he or she have certain cognitive deficits. This is of paramount importance for the prevention of maladjustment at school, and for adjusting the vector of the child's development.

The concept of developmental delay (DD) includes the slow-down in mastering speech and language, in motor skills, and in social-emotional and cognitive abilities (Bellman, Byrne, \& Sege, 2013). A study comparing age-related changes in cognitive functions in typically developing preschool children, with those of children with DD, is of considerable scientific and practical interest, since it not only brings us closer to understanding the mechanisms of mental development, but also provides us with the opportunity to recognize a potential trajectory of development in the norm and in DD. It also can help us to identify common patterns and markers of DD, including such forms of the latter identified under F80-F89 in the International Statistical Classification of Diseases and Related Health Problems 10th version, 2018.

It is known that the diagnosis of DD is not set in stone, since there is a high potential for rehabilitation when it is identified early enough: the earlier the diagnosis is made, the higher the chances of changing the child's developmental potential and achieving a successful outcome. It is also known that children with DD who do not receive a timely diagnosis and subsequent psycho-correction, are much more likely to develop behavioral problems than their peers with typical development (Crnic, Hoffman, Gaze, \& Edelbrock, 2004). For this reason, the possibility of rapid screening to identify children at risk for DD is very important. Therefore, we aimed to create a system for screening diagnostics of the mental development in five- to six-year-olds, specific to the Russian sample, which would utilize computer technologies to obtain reliable results on the basis of a relatively small set of data, with high sensitivity and specificity of the forecast.

\section{The Problem of Early Diagnosis of DD in Russia and Abroad}

The problem of DD has a special place in Russia. This is not only because the number of children with DD is constantly increasing, but especially due to advances in medicine which have helped premature and somatically weakened children survive. The primary variable is associated with the factor of the intervention time, on which the prospects of the child's development hugely depend.

It is known that children diagnosed with DD have a high potential for rehabilitation when corrective measures are timely and properly organized. However, a delay significantly increases the likelihood of more serious neurodevelopmental disorders (Levy, 2018). It is also known that the younger the child, the more neu- 
roplasticity his/her brain possesses, and the more compensatory possibilities are available (Kolb \& Gibb, 2011). Therefore, the study and prognosis of the development of cognitive functions are most important at an early age. However, given the goal of identifying predictive markers of cognitive development, we must take into account that the preschool age is characterized by intensive heterochronous development of mental functions (Glozman, 2013) and, accordingly, by the high variability of the structure of its indicators.

Various screening techniques have been successfully used in European countries for a long time (Frankenburg \& Dodds, 1967; Griffiths, 1970). But there are no attempts for elaborate screening of child mental development in Russia today that meet modern requirements for psychometrics, except our previous work (Nasledov, Miroshnikov, \& Tkacheva, 2018). The age slice being studied in scientific Russian publications begins with older preschoolers, and often DD is revealed only when they enter school, and this, unlike in most Western countries, is at the age of seven years, not five.

It would be possible to adapt one of the Western screening techniques to the Russian sample; however, the process is associated with significant financial costs. In addition, the translation and adaptation of the existing screening system would not permit reflection of the peculiarities of the Russian language, the Russian mentality, and the specificity of the current trends in the development and education of children in Russia. According to the results of cross-cultural research, children of the West and East differ in the dynamics of their cognitive development (Hughes, et al., 2014). Therefore, we set out to create a system of screening diagnosis of mental development of five- to six-year-olds specific to a Russian sample.

When assessing children's psychological readiness for school, Russian scientific publications commonly utilize such concepts as the level of development of basic cognitive processes such as: memory, attention, conceptual thinking, motor skills, and volitional aspects of cognitive performance (Kuindzhi, 2009). In Western literature, however, the criterion of school readiness is the formation of executive functions (Anderson \& Reidy, 2012). The key elements of the executive function are: the ability to extrapolate; arbitrary attention; behavioral control and self-regulation; working memory; the ability to plan and organize cognitive activities; and the use of effective strategies to solve problems (Willoughby, Wirth, \& Blair, 2011).

In addition, it is customary to distinguish some factors that affect mental development in early childhood. Among them are motor development (Frick \& Mohring, 2013); speech development (Goswami, 2015); random access memory (Cowan \& Alloway, 2009); attention (Stipek \& Valentino, 2015); spatial thinking (Hodgkiss et al., 2018); logical reasoning (Hollister, Sandberg, \& McCullough, 2010); and cognitive control mechanisms (Zanolie \& Crone, 2018). In accordance with our aim to develop a screening procedure, it was necessary to assess the contribution of these factors as predictors of mental development, in order to assess whether five- to sixyear-olds are typically developing, or at risk for DD.

Traditional works devoted to the diagnosis of cognitive development are based on classical ideas about the factor structure of intelligence, which is set a priori in the tests themselves. But there is a problem with such tests, because the subtests and factors are based on several predetermined types of tasks; this fact significantly limits the ability to study the real factor structure of the child's abilities (Macmann 
\& Barnett, 1994). Thus, a selection of the most effective methods of a child's training and education at a particular age, should be conducted on the basis of empirically confirmed data on the features of sensitive periods and heterochrony in the development of the child's cognitive functions. Accordingly, we chose a wider set of initial features, which were selected for our study by experts; this allowed for more flexible grouping into factors. Therefore, the factor analysis was carried out on a set of various separate tasks, which allowed for a more detailed analysis and more precise grouping of tasks into factors not limited a priori by the structure of the subtest.

The aim of our study was to identify the markers that have the most predictability value in estimating the probability of five- to six-year-old Russian children exhibiting DD, as well as to develop a short scale that allows accurate assessment of the risk for DD. Usually, screenings that evaluate mental development are divided into two categories: 1 ) those that require psychodiagnostics of the child and a survey of his or her parents, and 2) those that are entirely based on the parents' report (Humilton, 2006). In our case, the use of screening does not necessarily involve a survey of the parents (which minimizes the subjective component of the assessment), and is focused on rapid computerized diagnosis.

In one of the most well-known and widely used Western screenings, the Denver Developmental Screening Test (Dawson \& Camp, 2014), child development is evaluated by assessing the following domains, which are assumed to be vectors of development and related to the factor structure of intelligence: 1) large and fine motor skills; 2) speech development; and 3) communication and social adaptation. We assumed that the screening scales obtained in our research would correspond to Denver, and thus included the following domains the following domains: motor skills, speech development, and comprehension as a basis for adaptation and communication.

\section{Method}

\section{Materials}

Data collection was carried out using the same software "Longitude" (Ivanova \& Miroshnikov, 2001) as in our previous study (Nasledov, Miroshnikov, \& Tkacheva, 2018). This software included a huge bank of tasks, presented in accordance with the child's calendar age, and aimed at estimating a wide range of abilities in primary domains such as motor skills, social adaptation, and cognitive abilities. A psychologist worked with the child, conducted the evaluations, and filled out the test's electronic forms.

The content of the questions and tasks was typical for screenings and development tests, but at the same time very versatile, since the bank of tasks was created as the result of a survey of a large number of expert practitioner psychologists. In this study, the "Longitude" software was used only as a tool to collect raw data for subsequent analysis, without taking into account the grouping of tasks in the structure of the original method; thus we worked with completely "clean" data, not distorted by the a priori subtest or factor structure of the method used.

The baseline data included 847 dichotomous items (where $2=$ Yes, the child can perform a control action, and $1=$ No, the child cannot). Then we selected those 
items for which the answers to one of the two alternatives were no more than $95 \%$ for this sample (the results of performance of individual tasks and specialists' observations). Thus, 349 points were used for the five-year-olds and 292 points for the six-year-olds (see Table 1 for examples of the tasks).

\section{Procedure}

Diagnosis of the children (including assignment to the Norm or DD group) was carried out by experienced specialists from psychological and pedagogical counseling centers and pre-school institutions. It was done in the framework of planned work on individual support of children's development, with written parental consent, in the period from 2015 to 2019, in Saint-Petersburg, Murmansk, Belgorod, and other cities of Russian Federation. The diagnosis of DD was confirmed outside the scope of this study by experts, representatives of advisory centers, and commissions with the participation of neurologists, pathologists, and psychiatrists $(1=$ Norm, 2 = DD).

\section{The Sample}

The Norm sample was comprised of children without diagnosis who were attending ordinary preschool institutions. The DD sample consisted of children from specialized preschool institutions, already diagnosed with DD. In total, 604 five-yearold (527 Norm, 77 DD) and 628 six-year-old children (532 Norm, 96 DD) were surveyed, evenly represented in the age range of 1828 to 2554 days. Differences in the ages (measured in days) between the children of the Norm and DD groups were statistically insignificant.

\section{Statistical Data Analysis}

Statistical data analysis (as we did in our study of four- and five-year-olds (Nasledov et al., 2018)) was carried out for the following purposes: a) identification of a compact set of scales that predict the diagnosis most accurately (belonging to the group Norm or DD), and have sufficient reliability in relation to the different age ranges of five- to six-year-old children; b) interpretation of the relationships between predictors and the relative contribution of various scales in predicting the diagnosis; and c) development of statistical norms and an algorithm for rapid assessment of the probability of DD by applying the elaborated methodology. The analysis was carried out separately for the samples of five- and six-year-olds, in the same sequence, and using the same methods as in our previous study (Nasledov et al., 2018). All statistical analysis was performed using IBM SPSS software and AMOS version 25.

\section{Results}

\section{Selection of Variables}

To reduce the set of variables for each age, we used Discriminant Analysis (DA) (Klecka, 1980) of 349 variables for five-year-olds and 249 variables for six-year-olds with a stepwise method and grouping of the variable diagnosis (Norm or DD). As a result, the sets of variables that best distinguished the groups were obtained (Norm or DD): 52 variables for the five-year-olds, and 69 for the six-year-olds. 


\section{The Formation of Scales}

A stepwise procedure for selecting the variables was applied according to the following criteria, separately for each age group: 1) each of the remaining variables for factor analysis (FA) is included in only one factor, with a load of at least $0.4 ; 2$ ) each factor includes at least five such variables; 3 ) the calculated factors together provide maximum accuracy in predicting the diagnosis; and 4) the items included in each factor form a fairly reliable scale for internal consistency (Cronbach's alpha). For this purpose, in relation to each age group, FA with calculation of factor values was repeatedly applied to the selected variables, followed by DA, with the inclusion of calculated factors and the age of the child in days as predictors. As a result of the cyclic application of FA and DA for each age, a combination of predictors (factors) was revealed, the removal of each of which statistically significantly worsened the distinction between the classes ( $\mathrm{p}$ for $\mathrm{F}$ : inclusion $=.05$, exclusion $=.10$ ).

Table 1

Tasks examples

\begin{tabular}{|c|c|}
\hline Age & Tasks (Items) \\
\hline \multicolumn{2}{|c|}{ Scale "General awareness" } \\
\hline \multirow[t]{2}{*}{5 -year-old } & Aware of the sequence of days of the week. \\
\hline & Can give a correct answer to the question: "How old will you be in one year?" \\
\hline \multirow[t]{2}{*}{ 6-year-old } & Can answer the question: "What is the name of the town where you live?" \\
\hline & Can determine what time of year it is before or after it's named. \\
\hline \multicolumn{2}{|c|}{ Scale "Motor skills" } \\
\hline \multirow[t]{2}{*}{ 5-year-old } & Manage scissors to cut simple contours out of paper \\
\hline & Can fulfill tasks on a sheet of checkered paper, following instructions. \\
\hline \multirow[t]{2}{*}{ 6-year-old } & $\begin{array}{l}\text { Can jump on two feet forward and backward over a rope elevated above the } \\
\text { ground. }\end{array}$ \\
\hline & Can tie a simple knot according to a pattern. \\
\hline \multicolumn{2}{|c|}{ Scale "Logical reasoning" } \\
\hline \multirow[t]{2}{*}{ 5-year-old } & Capable of explaining why a car needs brakes. \\
\hline & Can answer the question: "What is the similarity between a hammer and an axe?" \\
\hline \multirow[t]{2}{*}{ 6-year-old } & Can give the correct answer to the question: "Why can I smell smoke?" \\
\hline & $\begin{array}{l}\text { Can correctly explain the use of the school bell, desks, and portfolio (correctly } \\
\text { described the purpose of each of these items). }\end{array}$ \\
\hline \multicolumn{2}{|c|}{ Scale "Sustained attention" } \\
\hline \multirow[t]{2}{*}{ 6-year-old } & Can focusing on a line and trace it from the beginning to the end (6 lines). \\
\hline & Can continue a drawing pattern from memory ( 3 patterns). \\
\hline \multicolumn{2}{|c|}{ Scale "Counting" } \\
\hline \multirow[t]{2}{*}{ 6-year-old } & Can call out numbers in direct order (from 11 to 19 ). \\
\hline & Can give the names of banknotes. \\
\hline
\end{tabular}


For each age (five and six years), a set of factors satisfying all the requirements was obtained: three factors, including 19 items (tasks) for five-year-olds; and five factors (35 items) for six-year-olds. Each factor consisted of six-seven items. It is important to note that for both ages, three factors were obtained that coincided as to the type of tasks (for five-year-olds, simpler; for six-year-olds, more complex): 1) "General Awareness" (completeness of the child's knowledge about the world); 2) "Motor Skills" (development of large and small differentiated motor skills); and 3) "Logical Reasoning" (the ability to draw logical conclusions based on comparison and taking into account the conditions of the task).

Two additional factors were identified for six-year-olds: 1) "Sustained attention" (the ability to direct attention selectively, to perceive specific stimuli, to stay focused for a certain time, and to prevent shifts of attention to irrelevant stimuli) (Anderson \& Reidy, 2012); and 2) "Counting" (the ability to encode numerical information in the form of words, the implementation of arithmetic operations). Examples of the tasks are presented in Table 1.

The whole sample was divided into two age groups (younger and older) according to the median age (in days) of the DD groups, in order to verify the stability of the forecast with a given set of predictors. The reliability of the scales (Cronbach's alpha) was separately defined for the five- and six-year-olds, and for parallel subgroups of the younger and older groups for each age. A sufficiently high reliability of each scale was found according to Cronbach's alpha (.779 to .922). Then the values of the scales were calculated as sums of their constituent items.

Due to the fact that the DD sample (task performance is worse) is much smaller than the Norm sample, the distributions of all scales for each age has a right (negative) asymmetry (asymmetry values for summary scales: -1.073 for five-year-olds; -1.563 for six-year-olds). Table 2 shows the results of comparing the Norm and DD samples for each age on the summarized scales. The size of the effect is huge (Cohen's $\mathrm{d}>>.8$ ); this indicates the high validity of the scales according to the criteria for separating the sample into Norm and DD groups.

Table 2

Comparison of means for summarized scales ${ }^{*}$

\begin{tabular}{ccccccc}
\hline Age & Diagnosis & N & Mean & Std. dev. & Cohen's d & $\eta^{2}$ \\
\hline \multirow{2}{*}{ 5-year-olds } & Norm & 527 & 33.9450 & 3.12825 & \multirow{2}{*}{2.914} & \multirow{2}{*}{487} \\
& DD & 77 & 24.4805 & 3.97893 & & \\
\hline \multirow{2}{*}{ 6-year-olds } & Norm & 532 & 64.9586 & 4.23711 & \multirow{2}{*}{3.398} & .600 \\
& DD & 96 & 48.3333 & 7.57512 & & \\
\hline
\end{tabular}

${ }^{*}$ Statistical significance of differences in the $t$-student criterion for all scales $p<0.001$ (adjusted for multiple checks)

Structural equation modeling (SEM) was used to check the following suppositions: 1) the obtained scales are indicators of the general factor (G-factor), which is the main predictor of the diagnosis; and 2) age has an indirect impact on the diagnosis through the G-factor. The verification was carried out on samples from each age group. 
Since the condition of multidimensional normality was not met (Multidimensional kurtosis ranged from 15.8 to 27.5; its C.R. from 22.7 to 30.8) in all cases, the Asymptotically Distribution Free method was used, as in our previous paper (Nasledov et al., 2018). All models confirmed the initial assumptions on the fit indices and the statistical significance of the parameters. All estimated parameters (regression coefficients, variance of exogenous variables, and covariance) were statistically significant $(\mathrm{p}<.05)$. An example of one model is shown in Figure 1 (for six-year-olds). The model for five-year-olds differs only in the absence of the scales "Sustained attention" and "Counting."

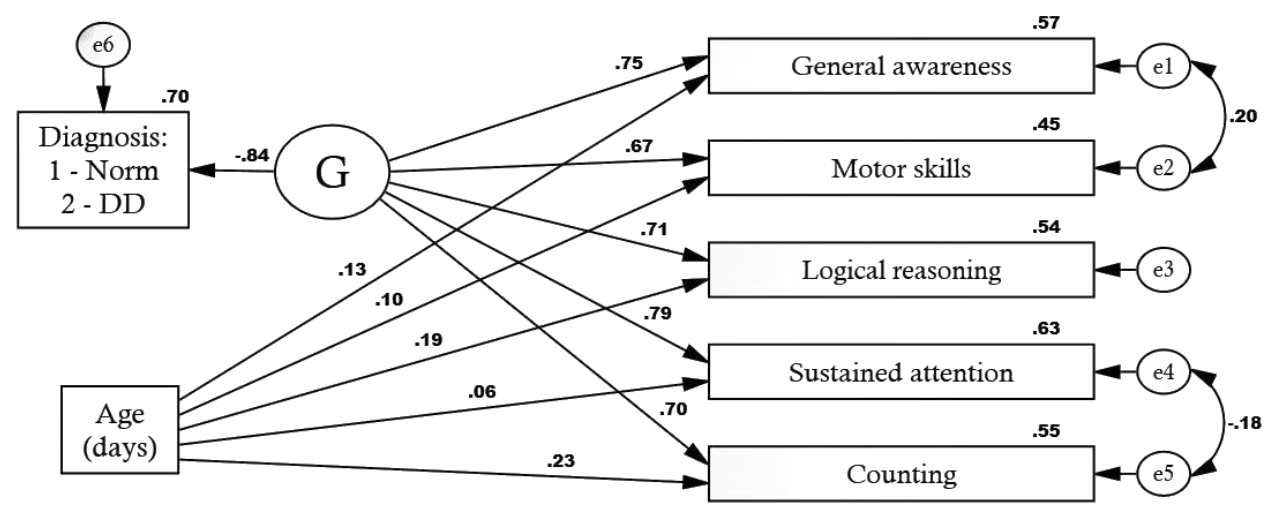

CMIN=9.476; $d f=8 ; p=.304 ; G F I=.995 ; C F I=.994 ;$ RMSEA $=.017 ;$ Pclose $=.939$

Figure 1. Structural diagnosis prediction model

Note. Numbers at arrows = standardized regression coefficients; numbers at contours of variables $=$ squares of multiple correlation.

For each age all the scales are indicators of a general factor $\mathrm{G}$, which is a predictor of the diagnosis and explains a significant percentage of the latter's variance. Thus, the diagnosis is directly affected by the general factor $G$, indicators of which are all the selected scales for each age. While age is a significant predictor of the diagnosis, it affects it indirectly, while factor $G$ has a direct impact on all indicators.

\section{Verification of the Relative Contribution of the Scales and Prognosis Accuracy}

DA was applied on the samples of each age, with predictors "Age" (in days) and scales S1-S3 on a sample of five-year-olds, and S1-S5 on a sample of six-yearolds. The standardized coefficients of discriminant functions, the absolute value of which is proportional to the contribution of each scale to the distinction between the Norm and the DD groups, are represented in Table 3.

The following factors, represented in descending order of contribution, were the most important in predicting the diagnosis (Norm or DD) for the sample of five-year-olds: "Logical reasoning," "Motor skills," and "General awareness." For the 
Table 3

The standardized coefficients of the discriminant functions ${ }^{*}$

\begin{tabular}{lcc}
\hline \multicolumn{1}{c}{ Variables } & \multicolumn{2}{c}{ Coefficients } \\
\hline S1 General awareness & .319 & 6-year-old \\
S2 Motor skills &. $\mathbf{5 6 3}$ & .188 \\
S3 Logical reasoning & .673 & .225 \\
S4 Sustained attention & No & .231 \\
S5 Counting & No &. $\mathbf{5 5 9}$ \\
Age & -.397 &. $\mathbf{3 9 6}$ \\
\end{tabular}

Note. ${ }^{*}$ Norm - on the positive, $D D$ - on the negative pole of the discriminant function.

The maximum coefficients of the absolute value are in bold.

sample of six-year-olds the ordering was: "Sustained attention," "Counting," "Logical reasoning," "Motor skills," and "General awareness." In other words, the higher the value on these scales, the more likely the child belongs to the norm group. Age in all cases contributes negatively to the differentiation of the groups. Given that the Norm and DD samples do not differ by age (in days), the negative contribution means that the difference between the groups on the selected scales increases with age.

The accuracy of the prediction of group allocation (Norm or DD) for the different ages, obtained as the result of applying DA to the two samples, is represented in Table 4.

Table 4

The prediction accuracy of the diagnosis (Norm/DD)

\begin{tabular}{|c|c|c|c|c|c|}
\hline \multirow{2}{*}{\multicolumn{2}{|c|}{ Original group membership }} & \multirow{3}{*}{$\begin{array}{c}\text { Diagnosis } \\
\text { Norm }\end{array}$} & \multicolumn{2}{|c|}{ Predicted group membership } & \multirow[b]{2}{*}{ In total } \\
\hline & & & Norm & DD & \\
\hline \multirow{4}{*}{$\begin{array}{l}5 \text {-year-olds } \\
\text { ( } 96.7 \% \text { of predicted is } \\
\text { true) }\end{array}$} & \multirow{3}{*}{ Count } & & 514 & 13 & 527 \\
\hline & & $\mathrm{DD}$ & 7 & 70 & 77 \\
\hline & & Norm & 97.5 & 2.5 & 100.0 \\
\hline & $\%$ & $\mathrm{DD}$ & 9.1 & 90.9 & 100.0 \\
\hline \multirow{4}{*}{$\begin{array}{l}\text { 6-year-olds } \\
\text { (94.4\% of predicted is } \\
\text { true) }\end{array}$} & \multirow{3}{*}{ Count } & Norm & 515 & 17 & 532 \\
\hline & & $\mathrm{DD}$ & 18 & 78 & 96 \\
\hline & & Norm & 96.8 & 3.2 & 100.0 \\
\hline & $\%$ & $\mathrm{DD}$ & 18.8 & 81.3 & 100.0 \\
\hline
\end{tabular}

Sensitivity measures the accuracy of predicting the diagnosis of DD, and specificity measures the accuracy of predicting the child belonging to the Norm group. For five-year-olds the prediction accuracy was $96.7 \%$ (sensitivity $90.9 \%$, specificity $97.5 \%$ ), and for six-year-olds it was $94.4 \%$ (sensitivity $81.3 \%$, specificity $96.8 \%$ ). 
Development of test scales was subordinated to the idea of achieving maximum accuracy in grouping the sample into groups Norm and DD. The main difficulty was to take into account the age, as during each period (in days), the measured indicators increase significantly. As in our previous study (Nasledov et al. 2018), this problem was solved with the use of DA: for each age, a discriminative function was constructed, i.e., an axis passing through the centroids of the shared classes (Norm, DD). The linear equation of this function relates the discriminant scores for each child (DF) to the values of the previously selected scales $(\mathrm{S} 1, \ldots, \mathrm{S} 5)$ and to age (in days).

The calculated discriminant scores for the entire sample for each age group were the raw scores to be scaled. From various options for nonlinear scaling, we chose 50-point percentile scales. Then the percentile limit which provided the most accurate allocation of the groups (Norm or DD) was determined. For five-yearolds, the upper limit of the 16th percentile (P16) was $94.8 \%$ sensitivity and $95.4 \%$ specificity. And for six-year-olds, the upper limit of P18 corresponded to $89.8 \%$ sensitivity and $94.5 \%$ specificity. Sensitivity and specificity of $70 \%$ to $80 \%$ are generally considered to be sufficient for good quality screening (Glascoe, 2005). Thus, the scales developed in our study have a fairly high accuracy.

\section{Discussion}

In classic tests of cognitive abilities, the content of the scales is determined by individual characteristics ("vectors of development") of typically developing children. The uniqueness of the scales we constructed in our project is that during the process of their elaboration, a vector was formed that polarized the children into two groups: Norm and DD.

We found that the Norm and DD groups among five-year-olds differed according to the following factors (represented in descending order of contribution): "Logical reasoning," "Motor skills," and "General awareness"; in six-year-olds they were "Sustained attention," "Counting," "Logical reasoning," "Motor skills," and "General awareness." It is important to point out that the most powerful predictor of DD for five-year-old children was the factor "Logical reasoning," and for sixyear-olds "Sustained attention." It should also be emphasized that the prognostic ability of revealed predictors is valid only in their totality.

Our results are consistent with our previous work on the development of screening scales for four- to five-year-old Russian children (Nasledov et al., 2018). We found that the scales for four- to five-year-olds coincided in terms of the factors included, but differed in terms of the complexity of the tasks; while the scale for six-year-olds included new factors related to executive functions, primarily sustained attention.

Sustained attention is included as one of the four main domains in the structure of executive functions, as discussed in Western literature; it emphasizes the role of the prefrontal cortex in the implementation of this function (Best, Miller, \& Jones, 2009). The concept of sustained attention implies the ability to control attention, selectively perceive specific stimuli, stay focused for a certain period of time, and prevent shifts in attention to irrelevant stimuli (Anderson, \& Reidy, 2012). 
Apparently, it is the factor of sustainability of attention that is the decisive predictor of DD at the senior preschool age, since it is directly related to the morpho-functional maturation of the cerebral cortex. It is known that the level of sustainability of attention is the basis for academic success (Clark, Pritchard, \& Woodward, 2010). It is also believed that sustained attention is an essential part of executive functions, along with verbal abilities and behavioral control (Decker, Ezrine, \& Ferraracci, 2016). Interestingly, in our previous studies, which aimed to identify predictive markers for four- and five-year-olds (Nasledov et al., 2018), this factor was not found. This can be explained by the heterochronicity and staging of mental development, and, therefore, the age of six years can be considered a sensitive period of formation of sustained attention in normal ontogenesis.

The factor "Counting" appeared to be in the second place, according to its predictive power in the senior preschool age. It is interesting that this factor, as well as "Sustained attention," is detected for the first time at this age, and was not evident in the prognostic markers of DD for four- and five-year-olds. It is obvious that the formation of counting skills for Russian children is especially important in the senior preschool period, while at an earlier age the child is faced with the more relevant tasks of widening general awareness, improving the ability to reason, and developing motor skills. Counting assumes sufficient maturity of the frontal cortex and the established system of neural connections between the frontal and parietal cortex of both hemispheres, as well as satisfactory storage capacity and functionality of short-term and long-term memory (Qin, Cho, Chen, Rosenberg-Lee, Geary, \& Menon, 2014).

At the same time, it is known that such factors as the socio-economic status of the family, the parents' competence, and the culture of home education play a major role in facilitating children's counting skills (Berch et al., 2016). It was found that children with whom parents played a variety of mathematical games which required operations of recalculation and comparison, demonstrated higher rates of development of arithmetic skills than children from families where parents focused on training their spatial thinking (Hart, Ganley, \& Purpura, 2016). Similar data were obtained in another study, where the mastery of basic counting and comparison skills in early preschool age are powerful predictors of the formation of arithmetic skills later on (Long, Malone, Tolan, Burgoyne, Heron-Delaney, Witteveen, \& Hulmea, 2016).

At the same time, it is believed that the strategies of counting on the fingers are culturally conditioned, and that visual and verbal abilities play a key role in the development of such cognitive strategies (Bender, \& Beller, 2012). It has also been shown that counting on the fingers at a preschool age selectively predicts future mathematical abilities (Reeve, \& Humberstone, 2011). A longitudinal study on measuring the approximate sense of number and knowledge of the Arabic number system, showed that knowledge of Arabic numbers at the age of six years is a powerful longitudinal predictor of the growth of arithmetic skills later in life (Göbel, Watson, Lervåg, \& Hulme, 2014). This is because the coding of numerical information in words is important to obtaining and maintaining simple facts on addition and subtraction (De Smedt, Janssen, Bouwens, Verschaffel, Boets, \& Ghesquière, 2009). 
In third place, according to its predictive power for six-year-old children, was the factor "Logical reasoning;" recall that this came in first place for five-year-olds. It is noteworthy that logical reasoning is included in the second domain of executive functions: i.e., goal setting, along with the ability to plan, extrapolate, and strategically organize one's own cognitive activity (Handley, et al. 2004). This factor is the main predictor of DD in four- to five-year-olds (Nasledov et al., 2018). However, it shows its predictive significance in six-year-olds as well, as it illustrates the establishment of understanding as the ability to reason and determines the significance of information.

It is believed that the ability to generate ideas is also associated with the development of logical reasoning (de Chantal, \& Markovits, 2017). According to the results of a neuroimaging study of comprehension tasks requiring verbalization, there was high variability in the results for typically developing six-year-olds, while eight-year-old children were much more successful in task processing, and the variability of the results was lower (Rajagopal, Byars, Schapiro, Lee, \& Holland, 2014). This reflects the individual trajectories of maturation of the cerebral cortex at the senior preschool age.

Fourth place in the contribution to the prediction of group allocation (Norm or DD) was taken by the factor "Motor skills", which was also a significant predictor of DD for younger children. The results obtained on the prognostic importance of motor skills for cognitive development of the child were quite expected because the importance of motor development in preschoolers has been demonstrated in many studies. Thus, the relationship between motor development and speech manifestation (Van der Fels, te Wierike, Hartman, Elferink-Gemser, Smith, \& Visscher, 2013), as well as the formation of a sustained attention span and behavioral control (Diamond, \& Lee, 2011), was demonstrated. Data were obtained on the impact of the development of fine motor skills in six-year-olds on their academic success in arithmetic, but not in reading (Pitchford, Papini, Outhwaite, \& Gulliford, 2016).

A leading role for the family in the development of fine motor skills of preschool children was also found, and again, the data obtained are directly associated with the socio-economic status of the family (Gottschling-Lang, Franze, \& Hoffmann, 2013). It is believed that improving motor skills, such as learning and maintaining rhythms and finely differentiated movements in the preschool age, can accelerate the formation of cognitive skills (van der Fels et al., 2015). According to the results of a comparative neuroimaging study of typically developing seven- to eight-year-old children and children of the same age with DD, the most significant differences were found in the areas of the brain connected with motor skills, perception, and behavior control (Baglio et al., 2014).

In fifth place was the "General awareness" factor, which is also included in the structure of predictors of DD for the younger age group. The importance of this factor was quite expected, since the cognitive development of the child is accompanied by an expansion of general knowledge about the world, and the increasing understanding of substantive relationships between phenomena and occurrences of the world. The beginning of school education dictates certain requirements as to the level and depth of the child's knowledge about the world. It is not surprising that an assessment of the breadth and depth of the child's knowledge of the world is an indispensable component of the school readiness tests (Janus, \& Offord, 2007). 
Despite the fact that "Logical reasoning" and "Counting" stood out as separate factors, the empirical data showed a causal relationship between the development of logical abilities and mastering arithmetic in six-year-olds. Thus, it was shown that a well-developed ability for logical reasoning predicted success in mathematical achievements over 16 months of primary school education (Nunes, Bryant, Evans, Bell, Gardner, Gardner, \& Carraher, 2007). It was also reported that the development of counting skills is associated with more general cognitive abilities, such as working memory, sustained attention span, and other components of executive functions, among which are the essential ones of planning and control; it is emphasized that children with DD suffer from a deficit of these functions (Belanger, \& Caron, 2018).

To summarize: In our study, we focused on exploring the factor model of cognitive and psycho-motor developmental vectors in typically developing preschoolers and children with DD. We obtained our data using SEM, whose screening scales were built for quick identification of groups at risk for DD, with high prognostic ability, because they reflect the current trends in cognitive development of Russian children. The unique characteristic of our elaborated scales comes from the use of computer technology in the data collection; similar studies, like the adaptive intelligence test AID, use tables. (Kubinger, Reif, \& Yanagida, 2011). Thus, we could take into account the individual specificities of the tasks relative to their level and complexity, and the choice of tasks in relation to the child's calendar age, which greatly improves the monitoring procedure.

\section{Conclusion}

Our study resulted in the development of a computer-based screening program to measure the cognitive development of preschoolers, which is easy and quick to use, and allows us to identify the "risk group" among five- to six-year-old children with high accuracy (the sensitivity of the forecast was not less than 94\%). Thus, we hope that the use of such screening will help to improve the system of early detection of DD risks, in order to allow timely intervention, and thus decrease the number of children in need of special attention from specialists.

\section{Limitations \& Future Research}

The use of our elaborated screening scales is intended for the timely diagnosis of the risk of DD in children when signs of DD have not yet become obvious, and thus nosological classification is quite difficult. It is important to note that the results of the screening are not the basis for precise diagnosis, but can serve as a first step to clarify the educational route and plan further assessments. In order to make an accurate diagnosis of DD, it is always necessary for the child to be examined by a specialist, regardless of symptoms revealed during the first computerized assessment.

In the future, we plan to expand the study sample to other age groups and create independent software that will optimize the process of data collection in the screening mode. However, in the case of detection of children at high risk for DD, more precise individual psychodiagnosis will be required to clarify the etiology and nosological type of $\mathrm{DD}$, and to prescribe the necessary corrective measures. 


\section{References}

Anderson, P., \& Reidy, N. (2012). Assessing executive function in preschoolers. Neuropsychology Review, 22, 4, 345-360. https://doi.org/10.1007/s11065-012-9220-3

Baglio, F., Cabinio, M., Ricci, C., Baglio, G., Lipari, S., Griffanti, L., ... Blasi, V. (2014). Abnormal development of sensory-motor, visual temporal and parahippocampal cortex in children with learning disabilities and borderline intellectual functioning. Frontiers in Human Neuroscience, 8(806). http://doi.org/10.3389/fnhum.2014.00806

Belanger, S.A. \& Caron, J. (2018). Evaluation of the child with global developmental delay and intellectual disability. Paediatrics \& Child Health, 23(6), 403-410. https://doi.org/10.1093/pch/pxy093

Bellman, M., Byrne, O., \& Sege, R. (2013). Developmental assessment of children. BMJ, 346: e8687. https://doi.org/ 10.1136/bmj.e8687

Bender, A. \& Beller, S. (2012). Nature and culture of finger counting: Diversity and representational effects of an embodied cognitive tool. Cognition, 124(2), 156-182. https://doi.org/10.1016/j.cognition.2012.05.005

Berch, D.B., Geary, D.C., \& Koepke, K.M. (Eds.) (2016). Mathematical cognition and learning. Development of Mathematical Cognition: Neural Substrates and Genetic Influences, Elsevier, vol. 2.

Best, J.R., Miller, P.H., \& Jones, L.L. (2009). Executive Functions after Age 5: Changes and Correlates. Developmental Review, 29(3). 180-200. https://doi.org/10.1016/j.dr.2009.05.002

Clark, C.A.C., Pritchard, V.E., \& Woodward, L.J. (2010). Preschool executive functioning abilities predict early mathematics achievement. Developmental Psychology, 46(5), 1176-1191. https:// doi.org/10.1037/a0019672

Cowan, N., \& Alloway, T. (2009). Development of working memory in childhood. In M.L. Courage, \& N. Cowan (Eds.), The Development of Memory in Infancy and Childhood (pp. 303-342). Hove, East Sussex, UK: Psychology Press.

Crnic, K., Hoffman, C., Gaze, C., \& Edelbrock, C. (2004). Understanding the Emergence of Behavior Problems in Young Children with Developmental Delays. Infants and Young Children, 17(3), 223-235. https://doi.org/10.1097/00001163-200407000-00004

Dawson, P., \& Camp, B.W. (2014). Evaluating developmental screening in clinical practice. SAGE Open Medicine, 2, 2050312114562579. https://doi.org/10.1177/2050312114562579

Decker, S.L., Ezrine, G.A., \& Ferraracci, J. (2016). Latent dimensions of executive functions in early Childhood. Journal of Pediatric Neuropsychology, 2, 89-98. https://doi.org/10.1007/s40817-0160013-0

De Chantal, P.L. \& Markovits, H. (2017). The capacity to generate alternative ideas is more important than inhibition for logical reasoning in preschool-age children. Memory \& Cognition, 45(2), 208-220. https://doi.org/10.3758/s13421-016-0653-4.

De Smedt, B., Janssen, R., Bouwens, K., Verschaffel, L., Boets, B., \& Ghesquière, P., (2009). Working memory and individual differences in mathematics achievement: A longitudinal study from first grade to second grade. Journal of Experimental Child Psychology, 103(2), 186-201. https://doi. org/10.1016/j.jecp.2009.01.004.

Diamond, A. \& Lee, K. (2011). Interventions shown to Aid Executive Function Development in Children 4-12 Years Old. Science, 333(6045), 959-964. https://doi.org/10.1126/science.1204529

Frankenburg, W.K. \& Dodds, J.B. (1967). The Denver developmental screening test. The Journal of Pediatrics, 71(2), 181-191. https://doi.org/10.1016/S0022-3476(67)80070-2

Goswami, U. (2015). Children's Cognitive Development and Learning. Cambridge Primary Review Trust, University of York.

Frick, A., \& Mohring, W. (2013). Mental object rotation and motor development in 8- and 10-monthold infants. Journal of Experimental Child Psychology, 115, 708-720. https://doi.org/10.1016/j. jecp.2013.04.001

Glascoe, F.P. (2005). Standards for Screening Test Construction. Retrieved from http://www.aap.org/ sections/dbpeds/pdf/Standards\%20for\%20Screening\%20Test\%20 Construction.pdf

Glozman, J. (2013). Developmental Neuropsychology (Explorations in Developmental Psychology). The UK: Routledge. 
Göbel, S.M., Watson, S.E., Lervåg, A., \& Hulme, C. (2014). Children’s Arithmetic Development: It Is Number Knowledge, Not the Approximate Number Sense, That Counts. Psychological Science, 25(3), 789-798. https://doi.org/10.1177/0956797613516471

Gonzales, C.L.R., Mills, K.J., Genee, I., Li, F., Piquette, N., Rosen, N., \& Gibb, R. (2014). Getting the right grasp on executive function. Frontiers in Psychology, 5(285). https://doi.org/10.3389/ fpsyg.2014.00285

Gottschling-Lang, A., Franze, M., \& Hoffmann, W. (2013). Associations of Motor Developmental Risks with the Socioeconomic Status of Preschool Children in North-Eastern Germany. Child Development Research, article ID 790524. http://dx.doi.org/10.1155/2013/790524

Griffiths, R. (1970). The Abilities of Young Children. London, UK: University of London Press.

Handley, S.J., Capon, A., Beveridge, M., Dennis, I., \& Evans, J.St.BT. (2004). Working memory, inhibitory control and the development of children's reasoning. Thinking \& Reasoning, 10(2), 175-195. https://doi.org/10.1080/13546780442000051

Hart, S., Ganley, C.M., \& Purpura, D. (2016). Understanding the home math environment and its role in predicting parent report of children's math skills. PLOS ONE, 11(12), e0168227. https://doi.org/10.1371/journal.pone.0168227

Hodgkiss, A., Gilligan, K.A., Tolmie A.K., Thomas M.S.C., \& Farran, E.K. (2018). Spatial cognition and science achievement: The contribution of intrinsic and extrinsic spatial skills from 7 to 11 years. British Journal of Educational Psychology, 675-697. https://doi.org/10.1111/bjep.12211

Hodgkiss, A., Gilligan, K.A., Tolmie, A.K., Thomas, M.S.C., \& Farran, E.K. (2018). Lost in translation? Comparing British, Japanese, and Italian children's theory-of-mind performance, Child Development Research, 893492. http://dx.doi.org/10.1155/2014/893492

Humilton, S. (2006). Screening for developmental delay: Reliable, easy-to-use tools. Applied Evidence, 55(5), 415-422.

Ivanova, A.E. \& Miroshnikov, S.A. (2001). Metodicheskie materialy k ekspertnoi sisteme individual'nogo soprovozhdeniya "Longityud" [Methodical materials for the expert system of individual support "Longitude"]. St. Petersburg: St.-Peterb. Gos. Universitet.

Janus, M. \& Offord, D.R. (2007). Development and psychometric properties of the early development instrument (EDI): a measure of children's school readiness. Canadian Journal of Behavioural Science, 39(1), 1-22. https://doi.org/10.1037/cjbs2007001

Klecka, W.R. (1980). Discriminant Analysis. Beverly Hills, California: Sage Publications. https://doi. org/10.4135/9781412983938

Kolb, B., \& Gibb, R. (2011). Brain plasticity and behaviour in the developing brain. Journal of the Canadian Academy of Child and Adolescent Psychiatry, 20(4), 265-276.

Kubinger, K.D., Reif, M. \& Yanagida, T. (2011). Branched adaptive testing with a Rasch-modelcalibrated test: analysing item presentation's sequence effects using the Rasch-model-based LLTM, Educational Research and Evaluation, 17(5), 373-385, https://doi.org/10.1080/1380361 1.2011 .630549

Kuindzhi, N.N. (2009). Funktsional'naya gotovnost' rebenka k shkole: retrospektiva i aktual'nost' [Functional readiness of the child for school: retrospective and relevance.]. Vestnik rossiyskoy akademii meditsinskikh nauk [Bulletin of the Russian Academy of Medical Sciences], 5, 33-36.

Levy, Y. (2018). 'Developmental Delay' Reconsidered: The Critical Role of Age-Dependent, Co-variant Development. Frontiers in Psychology, 9, 503. https://doi.org/10.3389/fpsyg.2018.00503

Long, I., Malone, S.A., Tolan, A., Burgoyne, K., Heron-Delaney, M., Witteveen, K., \& Hulmea, C. (2016). The cognitive foundations of early arithmetic skills: It is counting and number judgment, but not finger gnosis, that count. Journal of Experimental Child Psychology, 152. https:// doi.org/10.1016/j.jecp.2016.08.005

Macmann, G.M., \& Barnett, D.W. (1994). Some additional lessons from the Wechsler scales: A rejoinder to Kaufman and Keith. School Psychology Quarterly, 9, 223-236. https://doi. org/10.1037/ h0088288

Nasledov, A.D., Miroshnikov, S.A., \& Tkacheva, L.O. (2018). Elaboration of Screening Scales for Early Diagnosis of Developmental Delay in Four- to Five-Year-Old Children in Russia. Psychology in Russia: State of the Art, 11(4), 166-176. https://doi.org/10.11621/pir.2018.0411 
Nunes, T., Bryant, P., Evans, D., Bell, D., Gardner, S., Gardner, A., \& Carraher, J. (2007). The contribution of logical reasoning to the learning of mathematics in primary school. British Journal of Developmental Psychology, 25(1), 147-166. https://doi.org/10.1348/026151006X153127

Pitchford, N.J., Papini, C., Outhwaite, L.A., \& Gulliford, A. (2016). Fine motor skills predict math ability better than they predict reading ability in the early primary school years. Frontiers in Psychology, 7(783). https://doi.org/10.3389/fpsyg.2016.00783

Qin, S., Cho, S., Chen, T., Rosenberg-Lee, M., Geary, D.C., \& Menon, V. (2014). Hippocampal-neocortical functional reorganization underlies children's cognitive development. Nature Neuroscience, 17, 1263-1269. https://doi.org/10.1038/nn.3788

Rajagopal, A., Byars, A., Schapiro, M., Lee, G.R., \& Holland, S.K. (2014). Success rates for functional MR imaging in children. American Journal of Neuroradiology, 35, 2319-2325. https://doi. org/10.3174/ajnr.A4062

Reeve, R., \& Humberstone, J. (2011). Five- to 7-year-olds' finger gnosia and calculation abilities. Frontier in Psychology, 2, 359. https://doi.org/10.3389/fpsyg.2011.00359

Stipek, D., \& Valentino, R.A. (2015). Early childhood memory and attention as predictors of academic growth trajectories. J. Educ. Psychol., 107, 3, 771-788. https://doi.org/10.1037/edu0000004

Tzuriel, D., Isman, E.B., Klung, T., \& Haywood, H.C. (2017). Effects of teaching classification on classification, verbal conceptualization, and analogical reasoning in children with developmental language delays. Journal of Cognitive Education and Psychology, 16, 107-124. https://doi. org/10.1891/1945-8959.16.1.107

Van der Fels, I.M.J., te Wierike, S.C.M., Hartman, E., Elferink-Gemser, M.T., Smith, J., \& Visscher, C. (2015). The relationship between motor skills and cognitive skills in 4-16-year-old typically developing children: A systematic review. Journal of Science and Medicine in Sport, 18, 697-703. http://dx.doi.org/10.1016/j.jsams.2014.09.007

Van der Leij, A., van Bergen, E., van Zuijen, T., de Jong, P., Maurits, N., \& Maassen, B. (2013). Precursors of developmental dyslexia: an overview of the longitudinal Dutch Dyslexia Programme study. Dyslexia, 19(4), 191-213. https://doi.org/10.1002/dys.1463

Willoughby, M.T., Wirth, R.J., \& Blair, C.B. (2011). Contributions of modern measurement theory to measuring executive function in early childhood: an empirical demonstration. Journal of Experimental Child Psychology, 108(3), 414-435. https://doi.org/10.1016/j.jecp.2010.04.007

Zanolie, K., \& Crone, E.A. (2018). Development of Cognitive Control across Childhood and Adolescence. In J.T. Wixted (Ed.), Stevens' Handbook of Experimental Psychology and Cognitive Neuroscience (pp. 1-24). https://doi.org/10.1002/9781119170174.epcn405

Original manuscript received July 28, 2019

Revised manuscript accepted July 28, 2020

First published online September 15, 2020

To cite this article: Nasledov, A.D., Miroshnikov, S.A., Tkacheva, L.O., Zashchirinskaia, O.V., Goncharov, V.A. (2020). Elaborating Screening Scales for Early Diagnosis of Developmental Delay in Five- to Six-Year-Old Children in Russia. Psychology in Russia: State of the Art, 13(3), 18-33. DOI: $10.11621 /$ pir.2020.0302 